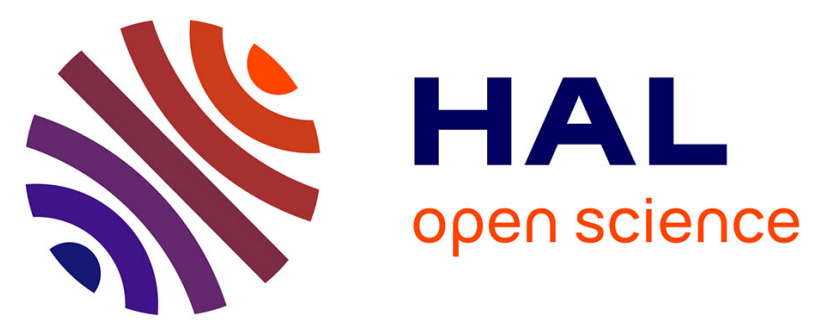

\title{
Exfoliative Toxins of Staphylococcus aureus
}

Ricardo B Mariutti, Natayme Rocha Tartaglia, Nubia Seyffert, Thiago Luiz de Paula Castro, Raghuvir K Arni, Vasco A. Azevedo, Yves Le Loir, Koji Nishifuji

\section{- To cite this version:}

Ricardo B Mariutti, Natayme Rocha Tartaglia, Nubia Seyffert, Thiago Luiz de Paula Castro, Raghuvir K Arni, et al.. Exfoliative Toxins of Staphylococcus aureus. The Rise of Virulence and Antibiotic Resistance in Staphylococcus aureus, In Tech Open Science, 206 p., 2017, Open Access Books " Life Sciences "Immunology and Microbiology, 978-953-51-2984-4. 10.5772/66528 . hal-01486492

\section{HAL Id: hal-01486492 https://hal.science/hal-01486492}

Submitted on 9 Mar 2017

HAL is a multi-disciplinary open access archive for the deposit and dissemination of scientific research documents, whether they are published or not. The documents may come from teaching and research institutions in France or abroad, or from public or private research centers.
L'archive ouverte pluridisciplinaire HAL, est destinée au dépôt et à la diffusion de documents scientifiques de niveau recherche, publiés ou non, émanant des établissements d'enseignement et de recherche français ou étrangers, des laboratoires publics ou privés.

\section{다(1)(2)}

Distributed under a Creative Commons Attribution - ShareAlikel 4.0 International 


\section{INTECH}

open science | open minds

\section{World's largest Science, Technology \& Medicine Open Access book publisher}
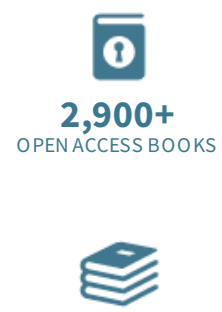

BOOKS

DELIVERED TO

151 COUNTRIES

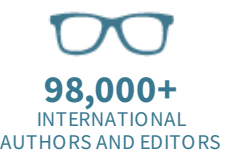

AUTHORS AND EDITORS

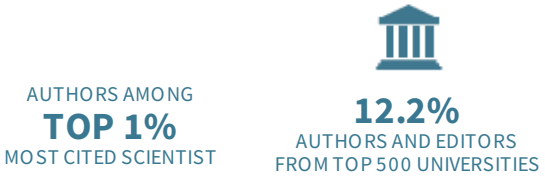

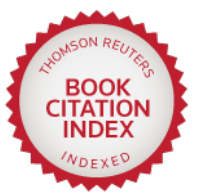

Selection of our books indexed in the Book Citation Index in Web of Science ${ }^{T M}$ Core Collection (BKCl)

Chapter from the book The Rise of Virulence and Antibiotic Resistance in Staphylococcus aureus

Downloaded from: http://www.intechopen.com/books/the-rise-of-virulence-andantibiotic-resis tance-in-i-staphylococcus-aureus-i-

Interested in publishing with InTechOpen? Contact us at book.department@intechopen.com 


\title{
Chapter 8
}

\section{Exfoliative Toxins of Staphylococcus aureus}

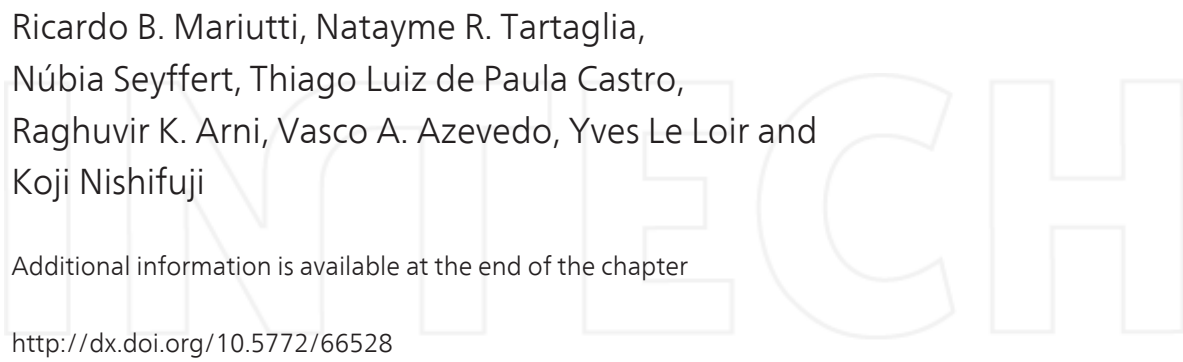

http://dx.doi.org/10.5772/66528

\begin{abstract}
Virulent strains of Staphylococcus aureus secrete exfoliative toxins (ETs) that cause the loss of cell-cell adhesion in the superficial epidermis. S. aureus ETs are serine proteases, which exhibit exquisite substrate specificity, and their mechanisms of action are extremely complex. To date, four different serotypes of ETs have been identified and three of them (ETA, ETB and ETD) are associated with toxin-mediated staphylococcal syndromes related to human infections leading to diseases of medical and veterinary importance.
\end{abstract}

Keywords: epidermolytic diseases, Staphylococcus aureus, exfoliative toxins, Desmoglein 1, keratinocytes

\section{Introduction}

Staphylococcus aureus, a commensal and opportunistic microorganism, is capable of colonizing the skin and mucous of individuals and represents a global public health problem [1-3]. It has been described as the etiological agent of various diseases both in humans and animals and is the main representative bacteria of the genus Staphylococcus [4]. S. aureus is a versatile microorganism and is capable of quickly adapting to different environmental conditions [5, 6]. This microorganism secretes several virulence factors that are associated with its pathogenesis [2] and in facilitating access to sites in the host that are normally sterile [7]. Diseases caused by S. aureus do not necessarily originate only by direct tissue invasion, but may be due to the action of more than 30 exoproteins codified by the pathogen $[8,9]$.

The exfoliative toxins (ETs) also known as epidermolytic toxins, are serine proteases secreted by $S$. aureus that recognize and hydrolyze desmosome proteins in the skin. ETs have been 
described as exotoxins produced by certain S. aureus strains, in the epidermis of the host, that have been associated with the loss of keratinocytes and with the cell-cell adhesion, inducing peeling of the skin and blister formation [10-13].

In 1878, Baron Gottfried Rotter Von Rittershain described the clinical features of epidermal exfoliation in newborns [14]. The relationship between skin exfoliation and S. aureus was established in 1967 by Lyell [14-16] and in 1972 [17] epidermal detachment at the stratum granulosum was established by electron microscopy. The pathogenic role of those toxins was demonstrated in 1970 by Melish and Glasgow by using newborn mice as experimental models [18]. However, the protein capable of causing generalized exfoliation in mice, denominated as exfoliatin, was not isolated and purified until 1971 [19] and subsequently serotypes have been identified [20, 21].

The principal isoforms of exotoxins implicated in human skin damage are exfoliative toxin A (ETA) and exfoliative toxin B (ETB) [22]. Exfoliative toxin C (ETC) isolated from a horse infection has not been associated with human disease. In 2002, a new exfoliative toxin (ETD) was identified in a clinical sample of S. aureus [13]. Recent crystallographic studies indicated that the ETD-like protein isolated from ewe mastitis [23] is structurally homologous to ETA and ETB [24]. ETA is codified by the eta gene on chromosomal DNA, carried on the genome on a temperate phage, and ETB by the etb gene on a large plasmid DNA [22, 25, 26]. ETD is codified by the etd gene which is located chromosomally on a pathogenicity island [13].

The ETA and ETB serotypes are homologous, have molecular masses of approximately $27 \mathrm{kDa}$, and contain 242 and 246 amino acids, respectively [22] and present identical dermatologic symptoms [26, 27].The ETA serotype was described as being heat stable whereas the ETB serotype has been demonstrated to be heat labile. The ETC serotype with a molecular mass of $27 \mathrm{kDa}$ is also heat labile and causes exfoliation in mice and chickens [28].

\section{Exfoliative toxins and associated diseases}

ET-producing strains of $S$. aureus are related to localized epidermal infections such as bullous impetigo and generalized diseases like Staphylococal scalded skin syndrome (SSSS). Approximately $5 \%$ of all S. aureus strains produce exfoliative toxins, with ETA being most prevalent in Europe, Africa, and America and ETB being more common in Japan [26]. Most strains of S. aureus associated with SSSS in Europe and the United States belong to the type II phage group, such as 71 and 55/71, however, in Japan; most of the strains belong to other groups [15, 29]. In France, based on a retrospective study conducted between 1997 and 2007 [30], the mean incidence of SSSS cases was estimated to be 0.56 cases/year/million inhabitants.

Both ETA and ETB are distinguished by the extent of the damage caused in the epidermis $[29,30]$. SSSS clinical manifestations involve fever, skin hypersensitivity, and erythema followed by superficial blister formation and skin separation, leaving long areas of denuded skin [10, 31]. In the localized form, toxin production and formation of flaccid blisters with purulent fluid occur $[12,30]$. SSSS occurs mainly in newborns and children with occurrences in adults being rare [11,32]. The mortality rate in children submitted to immediate treatment is low [33]. 
The greater susceptibility of children has been attributed to the immature immune system, weak renal clearance of the toxin, and the fact that children are common carriers of microorganisms [30]. In the most severe cases, exfoliation may affect the entire corporal surface [33]. The quick and sensitive diagnosis of those infections may be performed using radioimmunoassays, enzyme-linked immunosorbent assays, the reverse passive latex agglutination assay [26] as well as the polymerase chain reaction (PCR) to amplify the genes that codify ETs.

When the ET serotypes and the clinical forms of the disease were correlated, the ETA toxin was found to be associated with bullous impetigo formation, whereas ETB was found to be associated with SSSS, a generalized manifestation [34]. The ETB plasmid has multiple genes that confer antibiotic resistance, which contributes to the increased resistance of $e t b$-positive S. aureus strains [35]. The etd-positive strains have been isolated mainly from patients with deep pyoderma [12].

In addition to S. aureus, Staphylococcus hyicus and Staphylococcus chromogenes are also associated with skin infections and produce exfoliative toxins [36]. In S. hyicus, ET production has been associated with exudative epidermitis (EE) in pigs [37]. The toxin also has the capacity to cleave swine desmoglein $[38,39]$. Clinical manifestations are characterized by exfoliation accompanied by epidermal cell separation, erythema, and serous exudation [40]. The isolated toxins of these clinical manifestations have been denominated as SHETA and SHETB [41] and ExhA, ExhB, ExhC [41], and ExhD [38, 42]. In 2007, a Staphylococcus sciuri strain, highly pathogenic and ExhC-positive, was described as the etiological agent of EE in pigs in China [43]. The ExhC recombinant protein $(\mathrm{rExhC})$ has induced necrosis in vitro and has caused skin lesions in newborn mice [44].

Currently many phylogenetically distant hosts are described as being susceptible to exfoliation caused by the same isoforms of ET, revealing a certain specificity for various host organisms [29]. Among six different ETs (SHETA, SHETB, ExhA, ExhB, ExhC, and ExhD) codified by S. hyicus, SHET toxins caused exfoliation in piglets and chicks, but not in mouse, rat, guinea pig, hamster, dog, or cat [30]. All four Exh toxins cause exfoliation in pigs, but only ExhA and ExhC cause it in neonatal mice [40, 42]. SCET exfoliative toxin of Staphylococcus chromogenes also induces exfoliation in two different hosts; pigs and chicks. Different hosts are also susceptible to EXI exfoliative toxin of Staphylococcus pseudintermedius that induces exfoliation in dogs and mice.

Infections by et-positive Staphylococcus intermedius in dogs can also cause a pathology that resembles SSSS and EE [45]. A previous study described the distribution of toxin genes among phage types of animal isolates of $S$. aureus and the canine isolates of phage group II that harbored the eta gene [46].

In Japan, hospital-acquired methicillin-resistant S. aureus (HA-MRSA) strains frequently carry the $e t b$ gene [47] and, isolated samples of $e t b$-positive $S$. aureus have been encountered in strains with mecA, contrary to the isolated samples of eta-positive S. aureus [48].

ET-producing S. aureus strains (eta and $e t b$ ) are related to the clonal complex CC121 [49]. Infections with Staphylococci of this complex are associated with clinical features like impetigo, staphylococcal scalded skin syndrome, conjunctivitis, and exfoliative dermatitis [50]. 


\section{Structural biology and mechanism of exfoliative toxins}

The crystal structure of ETA was the first to be determined in atomic detail [51], followed by ETB [52] and by ETD [24] and currently, the atomic coordinates of six ET structures have been deposited with the Protein Data Bank (www.rcsb.org). The crystallographic structures of ETs have revealed much about their mechanisms of action, lack of hydrolytic activity against substrates in the native state, and the susceptibility of certain constituent layers of the epidermis to disruption by ETs.

\section{Similarities and differences among ETs and other serino proteinases}

Exfoliative toxins are glutamic-acid specific trypsin-like serine proteinases that share $50 \%$ sequence identity but display very low sequence identity with other serine proteases. The significant sequence identity of ETs is also reflected in the high structural similarity as evidenced by the low RMSD values of the superposed structures (ETA-ETB: 0.9, ETA-ETD: 1.3, and ETB-ETD: 0.6). Similar to other trypsin-like serine-proteinases, the three-dimensional structures of ETs are characterized by two six-stranded $\beta$-barrels domains, S1 and S2, whose axes lie roughly perpendicular to each other, a Greek key motif consisting of four antiparallel strands and $\mathrm{N}$ - and C-terminal extensions. The amino acids constituting the catalytic triad (His-Ser-Asp) and Thr190 and His213 which are characteristic of glutamate-specific serine proteinases are located at the junction of the S1 and S2 domains $[51,53]$.

ETs specifically cleave both mouse and human desmoglein 1 following glutamic acid 381, however only the presence of the Glu ${ }^{381}-\mathrm{Gly}^{382}$ bond, highly conserved in desmogleins, does not guarantee hydrolysis. The prerequisites for the exquisite specificity exhibited by ETs involves not only the presence of this cleavage site, but, also (1) the presence of the highly charged N-terminal alpha-helix, (2) the calcium dependent conformation of its substrate Dsg-1, and (3) existence of a specific sequence 110 residues upstream of the cleavage site of the substrate Dsg-1, characteristics that differentiate them from other typical glutamic-acidspecific serine proteinases of the chymotrypsin family.

(1) The highly charged N-terminal alpha-helix of ETs: The charge profile of N-terminal alpha-helix is significantly different, principally between ETD/ETA and ETB (Figure 1D) and its size also varies, containing 15, 11 and 12 residues in ETA, ETB and ETD, respectively.

This N-terminal extension which is unique to ETs and its deletion results in an inactive protein $[53,54]$ that interacts with residues in loop 2 thereby coordinating and determining the architecture of the S1 pocket and hence contributing to substrate specificity [51-53] by modifying the pocket entrance. The amino acid sequences (Figure 1D) and the conformations in loop2 (Figure 1E) are different in the ETs. In ETA (Figure 1E), this loop is longer than in ETB and ETD, additionally its Trp14 and Tyr18 present in the N-terminal 




Figure 1. Results of superpositioning of the three-dimensional structures: (A) ETD in green and a serine proteinase [PDB:2AIP] of the trypsin subfamily in pink. The loop 2 is dark blue in ETD, and the equivalent loop of serine proteinase is light blue. (B) ETA (blue), ETB (yellow) and ETD (green); amino acid sequences (C) and charge profile of the N-terminal helices (D) and its variation in the amino acid sequences. (E) The lengths of loop 2 in ETA (blue), ETB (yellow) and ETD (green) and its variation in the amino acid sequences $(\mathrm{F})$.

helix are buried deeper in the S1 pocket than in ETB which contains Lys and Glu and in ETD with Arg and Lys at these equivalent positions. In the other trypsin-like serine proteinases, the presence of a disulfide bridge determines the conformation of the pocket (Figure 1A).

(2) Calcium dependent conformation of Dsg-1: Dsg1 is a member of the cadherin supergene family [55] and most of these proteins require calcium to promote cell-cell adhesion and to ensure the proper conformation [56,57]. Unlike trypsin, ETs are not capable of cleaving heat-denatured Dsg1 or $\mathrm{Ca}^{2+}$ depleted Dsg1 [58] and circular dichroism demonstrates that ET specificity is dependent on calcium-stabilized conformation of Dsg1.

(3) Residues upstream of the Dsg-1 cleavage site are critical for its hydrolysis by ETA: ETA is able to bind but is unable to cleave canine Dsg1 and a sequence of 5 amino acids 110 residues upstream of the cleavage site are essential for the hydrolysis of Dsg1 by ETA [59]. Four of five of these critical residues are identical in human and mouse Dsg-1(Figure 2) and when replaced in canine Dsg-1 at its same position, the cleavage by ETA becomes susceptible. The recognition of this peculiar sequence (Q271-x-x-Y274-T275-I276-E277) is one of the factors that make ETs highly specific in Dsg cleavage, even among homologous Dsg-1s. This also demonstrated that E5 and EC4 do not exert any influence on the cleavage of the substrate and the chimeric human Dsg-3 containing swapped amino acids 214-398 of Dsg-1was cleaved by ETA. 


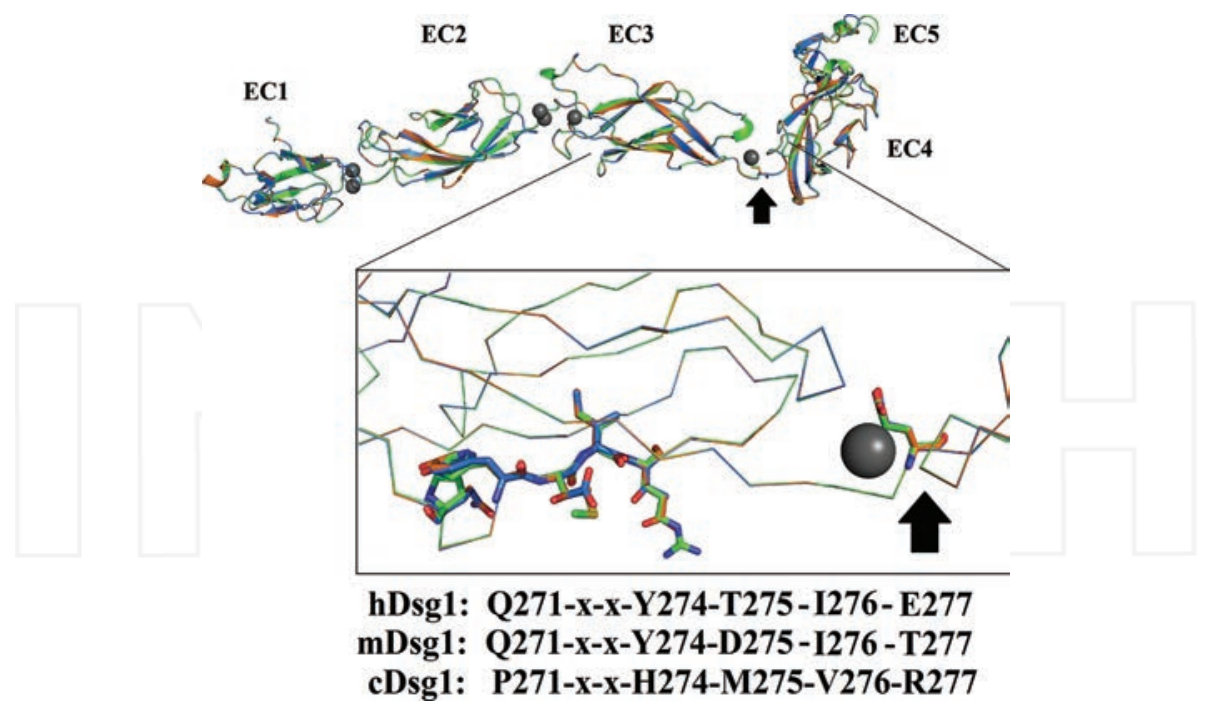

Figure 2. Results of superpositioning of the structural model of human Dsg1(orange), canine Dsg1 (green) and mouse Dsg1 (blue), purple spheres represent bound $\mathrm{Ca} 2+$, the susceptible glutamic acid is indicated by an arrow; amino acids sequence of the human, mouse, and canine Dsg1s upstream of the cleavage site; upstream location of the recognition sequence and the susceptible glutamic acid.

\section{Tyrosines 157 and 159 are essential for ETB activity}

Based on the results of site-directed mutagenesis, Sakurai et al. [60] concluded that the substitution of either Tyr 157 or 159 in ETB decreased exfoliative activity and the double mutation resulted in the complete loss of exfoliative activity and antigenicity. Interestingly, ETA does not possess either one of these tyrosines but contains Phe and His at these positions and in ETD these positions are occupied by Tyr and Thr.

\section{Why are the exfoliative toxins inactive in the native states?}

Gly193 is highly conserved in serine proteinases, however, in structures of ETs the peptide bond between residues 192 and 193 (chymotrypsin numbering) is flipped $180^{\circ}$ relative to the other serine proteases. Pro192 in ETA and ETD and Val192 (ETB) form hydrogen bonds with both the amide nitrogen atoms and the hydroxyl oxygen atoms of the catalytic serine residues interrupting the charge-relay-network. These enzymes can only be functional if this bond is ruptured and the conformation is restored as in other serine proteinases. 


\section{Molecular mechanisms of the $S$. aureus exfoliative toxin}

\subsection{S. aureus exfoliative toxins selectively and directly solubilize mouse and human desmoglein 1}

In 1970, Melish and Glasgow first investigated mechanisms of action of the exfoliative toxin (ET)-producing S. aureus in SSSS [11]. When the organisms isolated from SSSS patients were injected into neonatal mice, they cause epidermal blisters resembling those in the naturally occurred human disease. Several years later, two serotypes of ETs, ETA and ETB, which are capable of inducing epidermal blisters, were identified [21]. However, the exact molecular mechanisms of ET-causing epidermal blisters had long been unknown over the three decades.

In 2000, Amagai and colleagues established desmoglein 1 (Dsg1), a desmosomal cadherintype adhesion molecule and also known as pemphigus foliaceus autoantigen, as the target of S. aureus ETs [61]. They advocate this hypothesis based on the fact that histopathology of superficial epidermal blisters created by ET injection in mice resembles to those created by pemphigus foliaceus IgG. They revealed that immunostaining for the extracellular domain of Dsg1, but not that for Dsg3, is abolished in ETA-injected mouse skin. Moreover, an in vitro analysis revealed that ETA selectively solubilize the recombinant extracellular segments of human and mouse Dsg1 $(\alpha)$ produced by baculovirus. The same group also identified that $S$. aureus ETB and a newly identified ETD have similar enzymatic activity to solubilize Dsg1 [10, 12].

The site of blister formation by ETs could be explained in the context of tissue distribution of desmosomal cadherins (Figure 3) [13, 62].

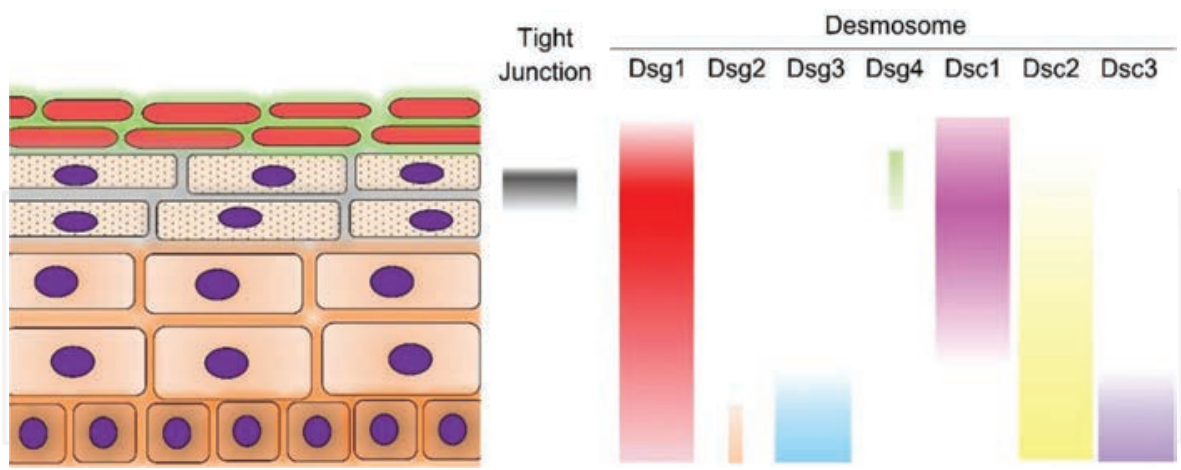

Figure 3. Distribution of functional tight junction and desmosomalcadherins in the epidermis. Dsg, desmoglein; Dsc, desmocollin. Functional tight junctions are located in the upper granular layer. Expression pattern of four isoforms of desmogleins (Dsg) and three isoforms of desmocollins (Dsc) is associated with differentiation level of keratinocytes. 
In humans, there are four subclasses of Dsg with different tissue distributions. Among them, Dsg2 is expressed in all desmosome-bearing tissues, whereas Dsg1 and Dsg3 are expressed preferentially in stratified squamous epithelia [63]. Dsg1 and Dsg3 are hypothesized to have compensatory effects [64]. For example, if both Dsg1 and Dsg3 express in the same epithelial cells, and adhesive function by Dsg1 is abolished, the loss of adhesive function can be compensated by intact Dsg3. In the epidermis, Dsg1 is expressed in the whole layers, whereas Dsg3 is expressed in basal and immediate suprabasal layers [65]. In contrast, in oral mucous membrane, both Dsg1 and Dsg3 are expressed in the whole layer, but the expression level of Dsg1 is relatively low compared with that of Dsg3 [63]. As Dsg2 and Dsg4 are expressed weakly in basal and upper granular layers, respectively [65], these molecules may have less ability to compensate the loss of Dsg1 function.

Desmocollin (Dsc) 1, another desmosomal cadherin is also expressed in superficial epidermis. It is hypothesized that Dsg1 and Dsc1 may have combinational effect on integrity of keratinocyte cell adhesion [66]: Abolishment of either Dsg1 by ETs or genetic ablation of Dsc1 causes dissociation of keratinocytes in the superficial layer of mouse epidermis [10, 13, 59, 67]. If adhesive function of Dsg1 is abolished by ETs, it may cause keratinocyte separation only in spinous-to-granular layers of epidermis, in which loss of adhesive function by Dsg1 could not be compensated by other Dsgs. This could be a reasonable explanation why ETs cause only superficial epidermal blisters in SSSS patients, although ETs produced in upper respiratory organs (e.g., tonsils), enter the circulatory system and induce toxemia [27].

\subsection{S. aureus ETs are unique glutamate-specific serine proteases that hydrolyze a single peptide bond within the extracellular segment of Dsg1}

Hanakawa et al. demonstrated that substitution of catalytic serine in ETA, ETB and ETD to alanine causes loss of their functions to solubilize Dsg1 [59]. Kinetic analysis of three ETs revealed $\mathrm{kcat} / \mathrm{Km}$ values in the range of $2-6 \times 104 \mathrm{M}^{-1} \mathrm{~s}^{-1}$, suggesting their efficient enzymatic activity to digest relatively large molecules. These findings indicate that three known S. aureus ETs are serine proteases that efficiently solubilize the extracellular segment of Dsg1.

The same group also investigated substrate-specificity of $S$. aureus ETs [58]. All three ETs cleave human and mouse Dsg1 $(\alpha)$ into two segments. Moreover, mouse has three isoforms of Dsg1 (Dsg1- $\alpha,-\beta$ and $-\gamma)[65,68]$, and ETA solubilize the extracellular segments of mouse Dsg1- $\alpha$ and $-\beta$, but not that of Dsg1- $\gamma$ in which glutamic acid residue 381 is substituted by lysine $[66,68]$. These findings indicate the specificity of the glutamic acid residue as the cleavage site of Dsg1 by ET.

S. aureus ETs are unique serine proteases that specifically and efficiently cleave only one peptide bond in the extracellular segment of Dsg1. The enzymatic properties of S. aureus ETs cause efficient and specific abolishment of a major epidermal adhesion molecule in selected mammalian species.

\subsection{Possible mechanisms of ET-associated keratinocyte dissociation}

Desmosomes composed of two major transmembrane cadherin-type adhesion molecules (Dsg and Dsc) and cytoplasmic plaque proteins that link between desmosomal cadherins and 
intracellular cytoskeletons. It has been long debated questions whether disruption of Dsgs alone by pemphigus autoantibodies is sufficient to cause keratinocyte dissociation, or subsequent disorganization of other desmosomal consituents in plasma membrane of keratinocytes is necessary [69].

To determine whether cleavage of the extracellular segment of Dsg1 by S. aureus ETs is sufficient to cause keratinocyte dissociation, our group has investigated the fate of desmosomal constituents in ETA-injected mouse skin [66]. We found that the amino-termini of Dsg1 is abolished in plasma membrane of murine epidermal keratinocytes, whereas cleaved carboxyl-termini of Dsg1 and the extracellular segment of Dsc1 remained on the surface of keratinocytes faced to blister cavity in the early phase of keratinocyte dissociation. Based on these findings, we proposed a theory that removal of the amino-termini of Dsg1 by ETs is sufficient to initiate in vivo keratinocyte dissociation.

Meanwhile, Simpson et al. proposed another theory for ET-induced keratinocyte dissociation through sequestration of plakoglobin (PG), a member of catenin family cytoplasmic protein, by ectodomain-deleted Dsg1 [70]. When truncated Dsg1, in which amino acids 1-381 were spliced to mimic ET-cleaved carboxy-termini of Dsg1, was expressed in primary human keratinocytes, it reduced mechanical strength of keratinocyte sheets in a dose-dependent manner, implicating a dominant-negative effect by truncated Dsg1. Truncated Dsg1 localized in close to intercellular borders and reduce endogenous desmosomal cadherin Dsc3 and desmosomal plaque protein desmoplakin in intercellular borders. In the same cells, PG localized in intercellular borders and seem to be associated with truncated Dsg1. Remarkably, triple-point mutation of the PG-binding region in the truncated Dsg1 restored mechanical integrity of keratinocyte sheets, implicating that PG binding to truncated Dsg1 is essential in disruption of desmosomes and subsequent keratinocyte dissociation.

Putting all these findings together, the authors advocate a theory that cleavage of Dsg1 by ETs initiate keratinocyte dissociation, while subsequent PG sequestration may contribute to the expansion of intercellular spaces between keratinocytes (Figure 4). Further accumulation of in vivo evidences to elucidate the role of PG in ET-inducing keratinocyte dissociation will be expected.

\subsection{How ET-producing S. aureus penetrate the epidermis through firm keratinocyte adhesion in the upper stratum granulosum?}

The aforementioned theory can satisfactorily explain how ETs cause blistering in SSSS, in which ETs access to the skin from dermal side. However, this theory cannot explain the mechanisms of blistering in bullous impetigo, in which ET-producing S. aureus enter the epidermis from the skin surface. It has been reported that ETs do not penetrate tight junction, an occlusive adhesive structure located at the upper granular layer (Figure 5) [71]. Then the question arises how ET-producing S. aureus invade the epidermis apart from a route of microwounds on the skin.

To address this issue, we recently established a mouse model of bullous impetigo [72]. $S$. aureus harboring etb gene was inoculated epicutaneously to murine inner pinnae after the stratum corneum was partially removed by tape stripping. Intraepidermal neutrophilic pustules containing intercellular staphylococci were successfully created in the mouse skin by 6 
1. Intact desmosome

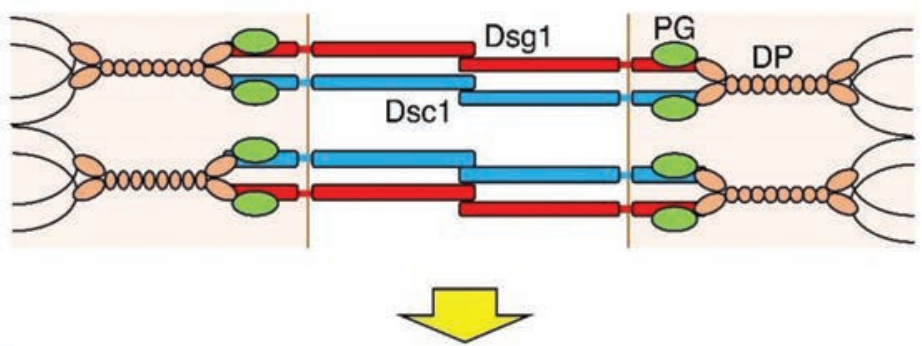

2. ET cleavage of desmoglein 1



3. Initial keratinocyte separation

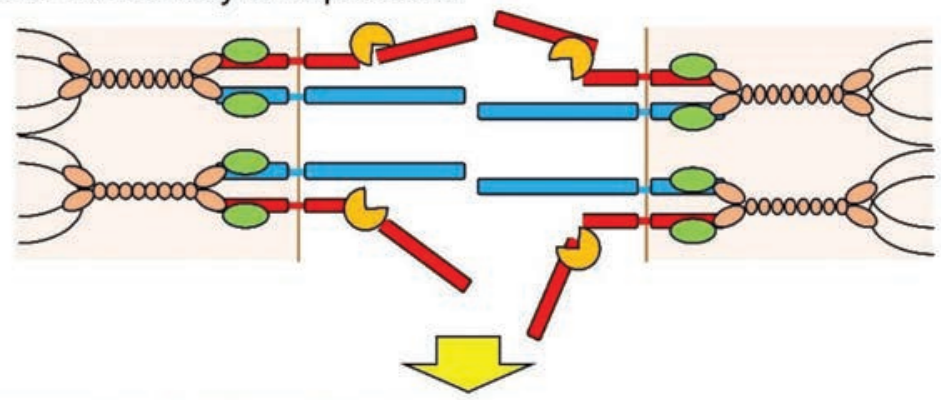

4. Expansion of intercellular spaces
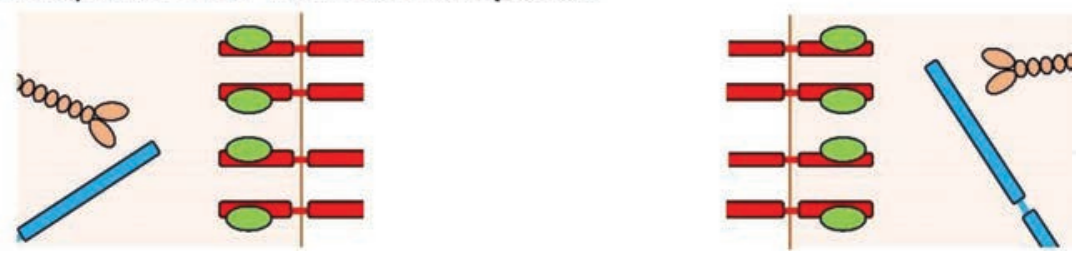

Figure 4. Possible mechanisms of ET-induced keratinocyte dissociation. PG, plakoglobin. Cleavage of the extracellular segment of Dsg1 initiates keratinocyte separation. Sequestration of PG by truncated Dsg1 and disintegrity of other desmosomal components are associated with expansion of the intercellular spaces between keratinocytes. 


\section{S. aureus adhere to the living epidermis}

2. Neutrophilic recruitment to the epidermis
3. Penetration of $S$. aureus through neutrophil-created intercellular gap

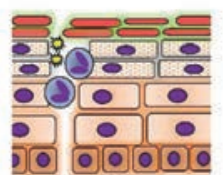

4. Expansion of blisters by ET cleavage of Dsg1 in superficial epidermis

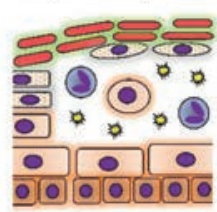

Figure 5. Proposed theory for bacterial cutaneous invasion and blistering in bullous impetigo. S. aureus harboring at gene adhere to the living epidermis recruits neutrophils. When neutrophils create intercellular gap between superficial keratinocytes, S. aureus produce ET to expand the blisters by cleavage of Dsg1.

hours after the inoculation. The size of intraepidermal pustules created by etb gene-harboring strains was significantly larger than those created by et gene-negative strains. Chronological study revealed that staphylococci invaded the epidermis after neutrophils infiltrated the skin. Moreover, if the neutrophilic infiltration was blocked by injection of cyclophosphamide, staphylococci in the epidermis were not recognized at all.

Based on these findings, we propose a novel hypothesis for percutaneous entry of ET-producing S. aureus in bullous impetigo. These strains may invade the epidermis through intercellular spaces created by skin-infiltrated neutrophils. In addition, once $S$. aureus invade the epidermis, ETs expand the interkeratinocyte spaces, which allows bacteria to skew neutrophils attack in blister cavity. Future studies to elucidate the molecular interactions that underlie neutrophilic epidermal infiltration in response to $S$. aureus adhere to living keratinocytes. In addition, the mechanisms how ET-producing penetrate the stratum corneum remains to be elucidated.

\section{Author details}

Ricardo B. Mariutti ${ }^{1}$, Natayme R. Tartaglia ${ }^{2,}{ }^{3}$, Núbia Seyffert ${ }^{4}$, Thiago Luiz de Paula Castro ${ }^{2}$, Raghuvir K. Arni ${ }^{1}$, Vasco A. Azevedo ${ }^{2}$, Yves Le Loir ${ }^{3}$ and Koji Nishifuji5*

*Address all correspondence to: kojimail@cc.tuat.ac.jp

1 Multiuser Center for Biomolecular Innovation, IBILCE/UNESP, São José do Rio Preto, SP, Brazil

2 Federal University of Minas Gerais, Belo Horizonte, MG, Brazil

3 Institut National de la Recherche Agronomique, Rennes, France

4 Federal University of Pará, Belém, Brazil

5 Tokyo University of Agriculture and Technology, Tokyo, Japan 


\section{References}

[1] Gordon, R.J., Lowy, F.D. Pathogenesis of methicillin resistant Staphylococcus aureus infection. Clin. Infect. Dis. 2008,46:S350-S359. DOI:10.1086/533591

[2] Ortega, E., Abriouel, H., Lucas, R., Gálvez, A. Multiple roles of Staphylococcus aureus enterotoxins: pathogenicity, superantigenic activity, correlation to antibiotic resistance. Toxins. 2010,2:2117-2131. DOI:10.3390/toxins2082117

[3] Popov, L., Kovalski, J., Grandi, G., Bagnoli, F., Amieva, M.R. Three-dimensional human skin models to understand Staphylococcus aureus skin colonization and infection. Front. Immunol. 2014,5:41. DOI:10.3389/fimmu.2014.00041

[4] Ishii, Y. Identification of biochemically atypical Staphylococcus aureus clinical isolates with three automated identification systems. J. Med. Microbiol. 2006,55:387-392. DOI:10.1099/jmm.0.46231-0

[5] Cepeda, J.A., Whitehouse, T., Cooper, B., Hails, J., Jones, K., Kwaku, F., Kibbler, C. Isolation of patients in single rooms or cohorts to reduce spread of MRSA in intensive-care units: prospective two centre study. Lancet. 2005,365:295-304. DOI:10.1016/ S0140-6736(05)17783-6; 10.1016/S0140-6736\%2805\%2917783-6

[6] Kniehl, E., Becker, A., Forster, D.H. Bed, bath and beyond: pitfalls in prompt eradication of methicillin-resistant Staphylococcus aureus carrier status in healthcare workers. J. Hosp. Infect. 2005,59:180-187. DOI:10.1016/j.jhin.2004.06.016

[7] Feil, E.J., Cooper, J.E., Grundmann, H., Robinson, D.A., Enright, M.C., Berendt, T., Peacock, S.J., Smith, J.M., Murphy, M., Spratt, B.G. How clonal is Staphylococcus aureus? J. Bacteriol. 2003,185:3307-3316. DOI:10.1128/JB.185.11.3307-3316

[8] Iandolo, J.J. Genetic analysis of extracellular toxins of Staphylococcus aureus. Ann. Rev. Microbiol. 1989,43(1):375-402. DOI:10.1128/MMBR.00055-13

[9] Marrack, P., Blackman, M., Kushnir, E., Kappler, J. The toxicity of staphylococcal enterotoxin B in mice is mediated by T cells. J. Exp. Med. 1990,1712:455-464. PMCID: PMC2187711

[10] Amagai, M., Yamaguchi, T., Hanakawa, Y., Nishifuji, K., Sugai, M., Stanley, J.R. Staphylococcal exfoliative toxin B specifically cleaves desmoglein 1. J. Invest. Dermatol. 2002,118:845-850. DOI:10.1046/j.1523-1747-2002.01751.x

[11] Melish, M.E., Glasgow, L.A. Staphylococcal scalded skin syndrome: the expanded clinical syndrome. J. Pediatr. 1971,78:958-967. DOI:10.1016/S0022-3476(71)80425-0; 10.1016/ S0022-3476\%2871\%2980425-0

[12] Yamaguchi, T., Nishifuji, K., Sasaki, M., Fudaba, Y., Aepfelbacher, M., Takata, T., Ohara, M., Komatsuzawa, H., Amagai, M., Sugai, M. Identification of the Staphylococcus aureus etd pathogenicity island which encodes a novel exfoliative toxin, ETD, and EDIN-B. Infect. Immun. 2002,70:5835-5845. DOI:10.1128/IAI.70.10.5835-5845.2002 
[13] Nishifuji, K., Sugai, M., Amagai, M. Staphylococcal exfoliative toxins: molecular scissors of bacteria that attack the cutaneous defense barrier in mammals. J. Dermatol. Sci. 2008,49:21-31. DOI:10.1016/j.jdermsci.2007.05.007

[14] Lyell, A. The staphylococcal scalded skin syndrome in historical perspective: emergence of dermopathic strains of Staphylococcus aureus and discovery of the epidermolytic toxin. A review of events up to 1970. J. Am. Acad. Dermatol. 1983,9:285-294. PMID: 6350386

[15] Lyell, A. A review of toxic epidermal necrolysis in Britain. Br. J. Dermatol. 1967,79:662-671. DOI:10.1111/j.1365-2133.1967.tb11434.x

[16] Lyell, A. Toxic epidermal necrolysis the scalded skin syndrome: a reappraisal. Br. J. Dermatol. 1979,100:69-86.DOI:10.1111/j.1365-2133.1979.tb03571.x

[17] Lillibridge, C.B., Melish, M.E., Glasgow, L.A. Site of action of exfoliative toxin in the staphylococcal scaled-skin syndrome. Pediatrics. 1972,50:728-738. PMID: 4263751

[18] Melish, M.E., Glasgow, L.A. The staphylococcal scalded-skin syndrome: development of an experimental model. N. Engl. J. Med. 1970,282:1114-1119. DOI:10.1084/jem.20111718

[19] Kapral, F.A., Miller, M.M. Product of Staphylococcus aureus responsible for the scaldedskin syndrome. Infect. Immun. 1971,4:541-545. PMCID: PMC416349

[20] Kondo, I., Sakurai, S., Sarai, Y. Purification of exfoliatin produced by Staphylococcus aureus of bacteriophage group 2 and its physicochemical properties. Infect. Immun. 1973,8:156-164.

[21] Kondo, I., Sakurai, S., Sarai, Y. New type of exfoliatin obtained from staphylococcal strains, belonging to phage groups other than group II, isolated from patients with impetigo and Ritter's disease. Infect. Immun. 1974,10:851-861. PMCID: PMC423032

[22] Lee, C.Y., Schmidt, J.J., Johnson-Winegar, A.D., Spero, L., Iandolo, J.J. Sequence determination and comparison of the exfoliative toxin A and toxin B genes from Staphylococcus aureus. J. Bacteriol. 1987,1699:3904-3909. PMCID: PMC213685

[23] Le Maréchal, C., Jardin, J., Jan, G., Even, S., Pulido, C., Guibert, J.M., Hernandez, D., François, P., Schrenzel, J., Demon, D., Meyer, E., Berkova, N., Thiéry, R., Vautor, E., Le Loir, Y. Staphylococcus aureus seroproteomes discriminate ruminant isolates causing mild or severe mastitis. Vet. Research. 2011,421:35-55. DOI:10.1186/1297-9716-42-35

[24] Mariutti, R.B., Souza, T.A.C.B., Ullah, A., Caruso, I.P., de Moraes, F.R., Zanphorlin, L.M., Tartaglia, N.R., Seyffert, N., Azevedo, V.A., Le Loir, Y., Murakami, M.T., Arni, R.K. Crystal structure of Staphylococcus aureus exfoliative toxin D-like protein: structural basis for the high specificity of exfoliative toxins. Biochem. Biophys. Res. Commun. 2015,467:171-177. DOI:10.1016/j.bbrc.2015.08.083.

[25] O'Toole, P.W., Foster, T.J. Molecular cloning and expression of the epidermolytic toxin a gene of Staphylococcus aureus. Microbial. Pathogenesis. 1986,1(6):583-594. PMID:3508500 
[26] Ladhani, S. Recent developments in staphylococcal scalded skin syndrome. Clin. Microbiol. Infect. Off. Publ. Eur. Soc. Clin. Microbiol. Infect. Dis. 2001,7:301-307. PMID: 11442563

[27] Bailey, C.J., de Azavedo, J., Arbuthnott, J.P. A comparative study of two serotypes of epidermolytic toxin from Staphylococcus aureus. Biochim. Biophys. Acta. 1980;624:111-120. PMID: 6773585

[28] Sato, H., Matsumori, Y., Tanabe, T., Saito, H., Shimizu, A., Kawano, J. A new type of staphylococcal exfoliative toxin from a Staphylococcus aureus strain isolated from a horse with phlegmon. Infect. Immun. 1994,62:3780-3785. PMCID: PMC303031

[29] Bukowski, M., Wladyka, B., Dubin, G. Exfoliative toxins of Staphylococcus aureus. Toxins. 2010,2:1148-1165. DOI:10.3390/toxins2051148

[30] Ladhani, S. Understanding the mechanism of action of the exfoliative toxins of Staphylococcus aureus. FEMS Immunol. Med. Microbiol. 2003,39:181-189. DOI:10.1016/ S0928-8244(03)00225-6

[31] Mueller, E., Haim, M., Petnehazy, T., Acham-Roschitz, B., Trop, M. An innovative local treatment for staphylococcal scalded skin syndrome. Eur. J. Clin. Microbiol. Infect. Dis. Off. Publ. Eur. Soc. Clin. Microbiol. 2010,29:893-897. DOI:10.1007/s10096-010-0927-x.

[32] Cribier, B., Piemont, Y., Grosshans, E. Staphylococcal scalded skin syndrome in adults. A clinical review illustrated with a new case. J. Am. Acad. Dermatol. 1994,30:319-324. PMID:8294590

[33] Jeyakumari, D., Gopal, R., Eswaran, M., Maheshkumar, C. Staphylococcal scalded skin syndrome in a newborn. J. Glob. Infect. Dis. 2009,1:45-47. DOI:10.1155/2015/901968

[34] Yamasaki, O., Yamaguchi, T., Sugai, M., Chapuis-Cellier, C., Arnaud, F., Vandenesch, F., Etienne, J., Lina, G. Clinical manifestations of staphylococcal scalded-skin syndrome depend on serotypes of exfoliative toxins. J. Clin. Microbiol. 2005,43:1890-1893. DOI:10.1128/ JCM.43.4.1890-1893.2005

[35] Hisatsune, J., Hirakawa, H., Yamaguchi, T., Fudaba, Y., Oshima, K., Hattori, M., Kato, F., Kayama, S., Sugai, M. Emergence of Staphylococcus aureus carrying multiple drug resistance genes on a plasmid encoding exfoliative toxin B. Antimicrob. Agents Chemother. 2013,57:6131-6140. DOI:10.1128/AAC.01062-13

[36] Futagawa-Saito, K., Makino, S., Sunaga, F., Kato, Y., Sakurai-Komada, N., Ba-Thein, W., Fukuyasu, T. Identification of first exfoliative toxin in Staphylococcus pseudintermedius. FEMS Microbiol. Lett. 2009,301:176-180. DOI:10.1111/j.1574-6968.2009.01823.x

[37] Wegener, H.C., Andresen, L.O., Bille-Hansen, V. Staphylococcus hyicus virulence in relation to exudative epidermitis in pigs. Can. J. Vet. Res. Rev. Can. Rech. Vét. 1993,57:119-125. PMCID:PMC1263605

[38] Fudaba, Y., Nishifuji, K., Andresen, L.O., Yamaguchi, T., Komatsuzawa, H., Amagai, M., Sugai, M. Staphylococcus hyicus exfoliative toxins selectively digest porcine desmoglein 1. Microb. Pathog. 2005,39:171-176. DOI:10.1016/j.micpath.2005.08.003 
[39] Nishifuji, K., Fudaba, Y., Yamaguchi, T., Iwasaki, T., Sugai, M., Amagai, M. Cloning of swine desmoglein 1 and its direct proteolysis by Staphylococcus hyicus exfoliative toxins isolated from pigs with exudative epidermitis. Vet. Dermatol. 2005,16:315-323. DOI:10.1111/j.1365-3164.2005.00474.x

[40] Ahrens, P., Andresen, L.O. Cloning and sequence analysis of genes encoding Staphylococcus hyicus exfoliative toxin types A, B, C, and D. J. Bacteriol. 2004,186:1833-1837. PMCID:PMC355961

[41] Sato, H., Watanabe, T., Higuchi, K., Teruya, K., Ohtake, A., Murata, Y., Saito, H., Aizawa, C., Danbara, H., Maehara, N. Chromosomal and extrachromosomal synthesis of exfoliative toxin from Staphylococcus hyicus. J. Bacteriol. 2000,182:4096-4100. DOI:10.1128/ JB.182.14.4096-4100.2000

[42] Andresen, L.O. Differentiation and distribution of three types of exfoliative toxin produced by Staphylococcus hyicus from pigs with exudative epidermitis. FEMS Immunol. Med. Microbiol. 1998,20:301-310. DOI:10.1111/j.1574-695X.1998.tb01140.x

[43] Chen, S., Wang, Y., Chen, F., Yang, H., Gan, M., Zheng, S.J. A highly pathogenic strain of Staphylococcus sciuri caused fatal exudative epidermitis in piglets. PLoS One 2007,2:147. DOI:10.1371/journal.pone.0000147

[44] Li, H., Wang, Y., Ding, L., Zheng, S.J. Staphylococcus sciuri exfoliative toxin C ExhC is a necrosis-inducer for mammalian cells. PLoS One. 2011,6:23145. DOI:10.1371/journal. pone.0023145.

[45] Terauchi, R., Sato, H., Endo, Y., Aizawa, C., Maehara, N. Cloning of the gene coding for Staphylococcus intermedius exfoliative toxin and its expression in Escherichia coli. Vet. Microbiol. 2003,94:31-38. DOI:10.1016/S0378-1135(03)00047-6

[46] Garbacz, K., Piechowicz, L., Mroczkowska, A. Distribution of toxin genes among different spa types and phage types of animal Staphylococcus aureus. Arch. Microbiol. 2015,197:935-940. DOI:10.1007/s00203-015-1127-y

[47] Motoshima, M., Yanagihara, K., Morinaga, Y., Matsuda, J., Sugahara, K., Yamada, Y., Kohno, S., Kamihira, S. Genetic diagnosis of community-acquired MRSA: a multiplex real-time PCR method for Staphylococcal cassette chromosome mec typing and detecting toxin genes. Tohoku J. Exp. Med. 2010,220:165-170. DOI:10.1620/tjem.220.165

[48] Nakaminami, H., Noguchi, N., Ikeda, M., Hasui, M., Sato, M., Yamamoto, S., Yoshida, T., Asano, T., Senoue, M., Sasatsu, M. Molecular epidemiology and antimicrobial susceptibilities of 273 exfoliative toxin-encoding-gene-positive Staphylococcus aureus isolates from patients with impetigo in Japan. J. Med. Microbiol. 2008,57:1251-1258. DOI:10.1099/ jmm.0.2008/002824-0.

[49] Larsen, A.R., Skov, R.L., Jarlier, V., Henriksen, A.S. Epidemiological differences between the UK and Ireland versus France in Staphylococcus aureus isolates resistant to fusidic acid from community-acquired skin and soft tissue infections. J. Antimicro. Chemother. 2008,613:589-594. DOI:10.1093/jac/dkm532 
[50] Kurt, K., Rasigade, J.P., Laurent, F., Goering, R.V., Žemličková, H., Machova, I., Ritchie, S. Subpopulations of Staphylococcus aureus clonal complex 121 are associated with distinct clinical entities. PLoS One. 2013,83:58155. DOI:10.1371/journal. pone. 0058155

[51] Vath, G.M., Earhart, C.A., Rago, J.V., Kim, M.H., Bohach, G.A., Schlievert, P.M., Ohlendorf, D.H. The structure of the superantigen exfoliative toxin A suggests a novel regulation as a serine protease. Biochemistry. 1997,36:1559-1566. DOI:10.1021/bi962614f

[52] Vath, G.M., Earhart, C.A., Monie, D.D., Iandolo, J.J., Schlievert, P.M., Ohlendorf, D.H. The crystal structure of exfoliative toxin B: a superantigen with enzymatic activity. Biochemistry. 1999,38:10239-10246. DOI:10.1021/bi990721e

[53] Cavarelli, J., Prévost, G., Bourguet, W., Moulinier, L., Chevrier, B., Delagoutte, B., Moras, D. The structure of Staphylococcus aureus epidermolytic toxin A, an atypic serine protease, at $1.7 \AA$ Å resolution. Structure. 1997,56:813-824. PMID:9261066

[54] Prévost, G., Couppié, P., Monteil, H. Staphylococcal epidermolysins. Curr. Opin. Infect. Dis. 2003,16(2):71-76. DOI:10.1097/01.aco.0000065073.06965.58

[55] Angst, B.D., Marcozzi, C., Magee, A.I. The cadherin superfamily: diversity in form and function. J. Cell Sci. 2001,114(4):629-641. PMID:11171368

[56] Kemler, R. From cadherins to catenins: cytoplasmic protein interactions and regulation of cell adhesion. Trends Genet. 1993,9(9):317-321. PMID:8236461

[57] Steinberg, M.S., McNutt, P.M. Cadherins and their connections: adhesion junctions have broader functions. Curr. Opin. Cell Biol. 1999,11(5):554-560. DOI:10.1016/ S0955-0674(99)00027-7

[58] Hanakawa, Y., Selwood, T., Woo, D., Lin, C., Schechter, N.M., Stanley, J.R. Calciumdependent conformation of desmoglein 1 is required for its cleavage by exfoliative toxin. J. Invest. Dermatol. 2003,121:383-389. DOI:10.1046/j.1523-1747.2003.12362.x

[59] Hanakawa, Y., Schechter, N.M., Lin, C., Nishifuji, K., Amagai, M., Stanley, J.R. Enzymatic and molecular characteristics of the efficiency and specificity of exfoliative toxin cleavage of desmoglein 1. J. Biol. Chem. 2004,279:5268-5277. DOI:10.1074/jbc.M311087200

[60] Sakurai, S., Suzuki, H., Saito, S., Konishi, Y., Machida, K., Kohno, M. New evidence that the Tyr-157 and Tyr-159 residues of Staphylococcal exfoliative toxin B are essential for its toxicity. Microbiol. Immunol. 1998,42:829-836. DOI:10.1111/j.1348-0421.1998.tb02358.x

[61] Amagai, M., Matsuyoshi, N., Wang, Z.H., Andl, C., Stanley, J.R. Toxin in bullous impetigo and staphylococcal scalded-skin syndrome targets desmoglein 1. Nat. Med. 2000,6:1275-1277. DOI:10.1038/81385

[62] Getsios, S., Huen, A.C., Green, K.J. Working out the strength and flexibility of desmosomes. Nat. Rev. Mol. Cell Biol. 2004,5:271-281. DOI:10.1038/nrm1356 
[63] Shirakata, Y., Amagai, M., Hanakawa, Y., Nishikawa, T., Hashimoto, K. Lack of mucosal involvement in pemphigus foliaceus may be due to low expression of desmoglein 1. J. Invest. Dermatol. 1998,10:76-78. DOI:10.1046/j.1523-1747.1998.00085.x

[64] Amagai, M. Autoimmunity against desmosomalcadherins in pemphigus. J. Dermatol. Sci. 1999,20:92-102. PMID: 10379702

[65] Mahoney, M.G.,Hu, Y., Brennan, D., Bazzi, H., Christiano, A.M., Wahl,J.K.3rd. Delineation of diversified desmoglein distribution in stratified squamous epithelia: implications in diseases. Exp. Dermatol. 2006,15:101-109. DOI:10.1111/j.1600-0625.2006.00391.x

[66] Nishifuji, K., Shimizu, A., Ishiko, A., Iwasaki, T., Amagai, M. Removal of amino-terminal extracellular domains of desmoglein 1 by staphylococcal exfoliative toxin is sufficient to initiate epidermal blister formation. J. Dermatol. Sci. 2010,59:184-191. DOI:10.1016/j. jdermsci.2010.07.010

[67] Chidgey, M., Brakebusch, C., Gustafsson, E., Cruchley, A., Hail, C., Kirk, S., Merritt, A., North, A., Tselepis, C., Hewitt, J., Byrne, C., Fassler, R., Garrod, D. Mice lacking desmocollin 1 show epidermal fragility accompanied by barrier defects and abnormal differentiation. J. Cell Biol. 2001,155:821-832. DOI:10.1083/jcb.200105009

[68] Brennan, D.,Hu, Y., Kljuic, A., Choi, Y., Joubeh, S., Bashkin, M., Wahl,J., Fertala, A., Pulkkinen, L., Uitto, J., Christiano, A.M., Panteleyev, A., Mahoney, M.G. Differential structural properties and expression patterns suggest functional significance for multiple mouse desmoglein 1 isoforms. Differentiation. 2004,72:434-449. DOI:10.1111/j.1432-0436.2004.07208009.x

[69] Amagai, M., Stanley, J.R. Desmoglein as a target in skin disease and beyond. J. Invest. Dermatol. 2012,132:776-784. DOI:10.1038/jid.2011.390

[70] Simpson, C.L., Kojima, S., Cooper-Whitehair, V., Getsios, S., Green, K.J. Plakoglobin rescues adhesive defects induced by ectodomain truncation of the desmosomal cadherin desmoglein 1: implications for exfoliative toxin-mediated skin blistering. Am. J. Pathol. 2010,177:2921-2937. DOI:10.2353/ajpath.2010.100397

[71] Ouchi, T., Kubo, A., Yokouchi, M., Adachi, T., Kobayashi, T., Kitashima, D.Y., Fujii, H., Clausen, B.E., Koyasu, S., Amagai, M., Nagao, K. Langerhans cell antigen capture through tight junctions confers preemptive immunity in experimental staphylococcal scalded skin syndrome. J. Exp. Med. 2011,208:2607-2613. DOI:10.1084/jem.20111718

[72] Imanishi, I., Hattori, S., Hisatsune, J., Ide, K., Sugai, M., Nishifuji, K. Staphylococcus aureus penetrate the inter-keratinocyte spaces created by skin-infiltrating neutrophils in the mouse model of impetigo. Vet Dermatol. 2016 Nov 13. doi: 10.1111/vde.12398. [Epub ahead of print] 